\title{
Influence of aquatic exercise training on balance in young adults
}

\author{
Influência do treinamento de exercícios aquáticos \\ sobre o equilíbrio em adultos jovens
}

\author{
Luana Mann $^{[a]}$, Julio Francisco Kleinpaul ${ }^{[b]}$, Carlos Bolli Mota ${ }^{[c]}$, Saray Giovana dos Santos ${ }^{[d]}$ \\ [a] MSc, researcher, Universidade Federal de Santa Catarina, professor, Faculdade São Francisco de Barreiras, Barreiras, BA - \\ Brazil, e-mail: luanamann@gmail.com \\ [b] MSc, professor, Faculdade São Francisco de Barreiras, Barreiras, BA - Brazil, e-mail: juliofk@gmail.com \\ [c] PhD, professor, Universidade Federal de Santa Maria, Centro de Educação Física e Desportos, Santa Maria, RS - Brazil, \\ e-mail: bollimota@gmail.com \\ [d] PhD, professor, Universidade Federal de Santa Catarina, Florianópolis, SC - Brazil, e-mail: senseisaray@hotmail.com
}

\begin{abstract}
Introduction: Physical exercise programs have been suggested to soften or reverse balance deficits and postural deviation. Objective: This study investigated the influence of a systematic aquatic exercise program on body balance. Method: Healthy young adult volunteers of both genders, aged 18-30 years were assessed. The experimental group (EG, $\mathrm{n}=20$ ) was subjected to 24 sessions of aquatic exercises of 50 minutes long, performed three times a week, and the control group (CG, $n=25)$ suffered no intervention. A 3-D force platform was used to calculate the center of pressure displacement (COP) in anteroposterior and mid-lateral directions with or without visual information. The individuals were assessed in pre or post-training. Results: The results demonstrated a decrease in body oscillation in both visual conditions, with post-training values lower than pre-training ones. Visual information was not expressive for EG post-training. Conclusion: It was concluded that the program was effective for body balance improvement.
\end{abstract}

Keywords: Balance. Training. Vision. 


\section{Resumo}

Introdução: Programas de exercícios físicos têm sido propostos para amenizar ou reverter déficits de equilíbrio e desvios posturais. Objetivo: Neste trabalho investigou-se a influência de um programa de exercícios aquáticos sistemático sobre o equilíbrio corporal. Método: Foram avaliados indivíduos adultos jovens saudáveis voluntários de ambos os sexos com idades entre 18 e 30 anos. O grupo experimental (GE, $n=20)$ foi submetido a 24 sessões de exercícios aquáticos realizados três vezes por semana, com 50 minutos de duração, e o grupo controle $(G C, n=25)$ não sofreu intervenção. Uma plataforma de força 3- $D$ foi utilizada para calcular o deslocamento do centro de pressão (COP) nas direções anteroposterior e médio-lateral com e sem a informação visual. Os indivíduos foram avaliados em pré e pós-treinamento. Resultados: Os resultados demonstraram uma diminuição da oscilação corporal em ambas as condições visuais, com os valores de pós-treinamento sendo inferiores aos do pré-treinamento. A informação visual não foi significativa no pós-treinamento para o GE. Conclusão: Conclui-se que o programa foi efetivo para a melhora do equilíbrio corporal.

Palavras-chave: Equilíbrio. Treinamento. Visão.

\section{Introduction}

The maintenance and control of body posture during static and dynamic situations are essential during sports and daily activities of human beings. To ensure its proper operation, the Central Nervous System (SNC) generates muscle activities patterns, necessary to regulate the relationship between the center of body mass and the base of support, through information collected, mainly from sensorial systems (visual, somatosensory and vestibular) that act as a way of transmitting specific information related to body position in space, falling to the central nervous system the task of organizing the information and controlling both static and dynamic body posture (1).

Health problems caused by balance deficit and/ or falls are some of the main public health problems, making the individual lose their autonomy and, consequently, decreasing their life quality. In Brazil, ca. $30 \%$ of the elderly fall at least once a year (2). Falls reflect the incapacity of the postural control system in recovering from a disturbance, i.e., keeping the center of gravity projection (CG) within stability limits (3).

From the start of adulthood until intermediate years, sensory and motor changes are small and gradual, almost imperceptible. After the age of 45, these changes become more distinct, reaching sensory systems (visual, vestibular and somatosensory) and motor capabilities such as strength, flexibility, reaction time, balance and coordination, thus making the elderly the age group most stricken with balance problems $(4,5)$.

Literature shows evidence that continuous physical exercise can contribute to gain of muscle strength, minimizing existing balance deficits $(6,7$, $8,9,10,11)$. The practice of aquatic physical exercises is considered an improvement factor on physical capabilities, increasing coordination, agility, body synesthesia, perception, body schema, action and reaction velocity, and better balance and directionality $(10,12,13,14)$.

Considering the importance of body balance as a component of an autonomous daily life, as well as the scarcity of experimental studies that verify the effectiveness of aquatic exercises on body balance in healthy young individuals, the issue investigated in this study was: Does the practice of aquatic exercises interferes in static body balance with and without manipulation of the visual system?

To be able to answer this question, this study intended to analyze the influence of aquatic exercises on static body balance with and without visual manipulation in healthy young adults.

This study is justified by the need of knowing the effects of periodically practicing physical exercises in water for healthy young adult individuals, since its results may, in the future, be a safe and trustworthy source for the implementation of rehabilitation and prevention programs to be developed, considering it'll identify the possible benefits of the application of aquatic programs to posture control systems. 


\section{Method}

This study is characterized as one of experimental nature, with control group design of pre and post-training.

Young adult individuals (college students) of both genders of the community were assessed. Initially, 45 individual volunteers of an aquatic initiation project formed the experimental group (the one subjected to the aquatic exercises program). The control group (CG - the one that didn't suffer intervention) was selected from individuals that voluntarily offered to participate in this study, in a total of 50 individuals.

To select which of these volunteers would be part of the study, the following inclusion criteria were applied:

\section{EG and CG inclusion criteria:}

- To be a college student;

- Aged 18-30 years;

- Without any kind of musculoskeletal impairment or vestibular problem;

- Without lumbar pain;

- Not physically active (determined by anamnesis), in the CG case, they should remain inactive until the post-test. It was considered inactive those who didn't perform systematical physical exercises with minimal frequency of three times per week;

- Availability to report for data collection.

Specifically for EG:

- Not adapted to liquid environment;

- Availability for program activities with due frequency (80\% minimum);

- Not practicing any other periodic physical activity.

At the end of this stage 27 individuals were considered fit to participate in this study (EG) and 35 individuals were selected for the control group (CG).

Individuals who didn't meet the inclusion criteria, who didn't have a proper program frequency or who didn't attend the data collection were excluded from this study. In the end, the EG consisted of 20 individuals, 9 male and 11 female, with average age of $20.91 \pm$ 2.21 years, average body stature of $1.70 \pm 0.04 \mathrm{~cm}$ and average body weight of $685.22 \pm 59.41 \mathrm{~N}$, and the CG was composed by 25 individuals (who participated in all stages of the test), 13 male and 12 female, with average age of $21.75 \pm 2.34$, average body stature of $1.67 \pm$ $0.07 \mathrm{~cm}$ and average body weight of $669.95 \pm 69.37 \mathrm{~N}$.

To guarantee the internal and external validity of this study, a control group was used with similar characteristics to the experimental group, such as age group, body weight and stature, and went through the same evaluations that the experimental group was subjected, but without intervention, receiving the same instructions in all data collection stages, performed in laboratory environment, with an acclimatization period. The data collection instrument was the same for both groups, and there were few test repetitions to avoid learning with them. To prevent sampling loss, a relatively large set was used for both groups, so that, at the end of the study, the capacity for comparison between the groups and on the effectiveness or not of the program would be possible. The same researchers who applied the training performed the data collection.

The aquatic exercises training was considered as an independent variable in this study, the static body balance as a dependent variable, the practice of physical exercises previous to the beginning of training as a moderating variable, the existence of an asymptomatic pathology in any sensory systems as an intervening variable, and exercises volume and intensity as control variables.

\section{Body balance biomechanical assessment}

After the first contacts with the individuals and preceding the data collection, they signed a Free and Informed Consent Form, agreeing to participate in the study, which was approved by the Institution's ethical committee and developed under the process number 23081.007411/2007-53, fulfilling the ethical principles included in the Declaration of Helsinki, in addition to complying with the present legislation.

The static body balance was assessed with computer stabilography. A three-dimensional force platform (OR6-5 AMTI, Advanced Mechanical Technologies, Inc., USA) was used to evaluate the center of pressure position (COP) during static posture. The COP expresses the soil's reaction force resulting position, indicating the neuromuscular answers for body oscillation due to changes in the center of gravity position (15).

The individuals' position was standardized as having both feet on the platform, arms relaxed beside 
the torso, staring at a reference point placed on the wall in front at eye level and two meters away from the force platform. The individuals were assessed with their limbs placed at hip width, as shown in Figure 1, in two conditions: eyes open (OE) and eyes closed (CE). Three attempts were made in each condition totalizing six attempts for each individual, pre and post-training. The data acquisition time for each try was of 30 seconds after visual stability of the center of pressure (COP), and an acquisition frequency of $100 \mathrm{~Hz}$.

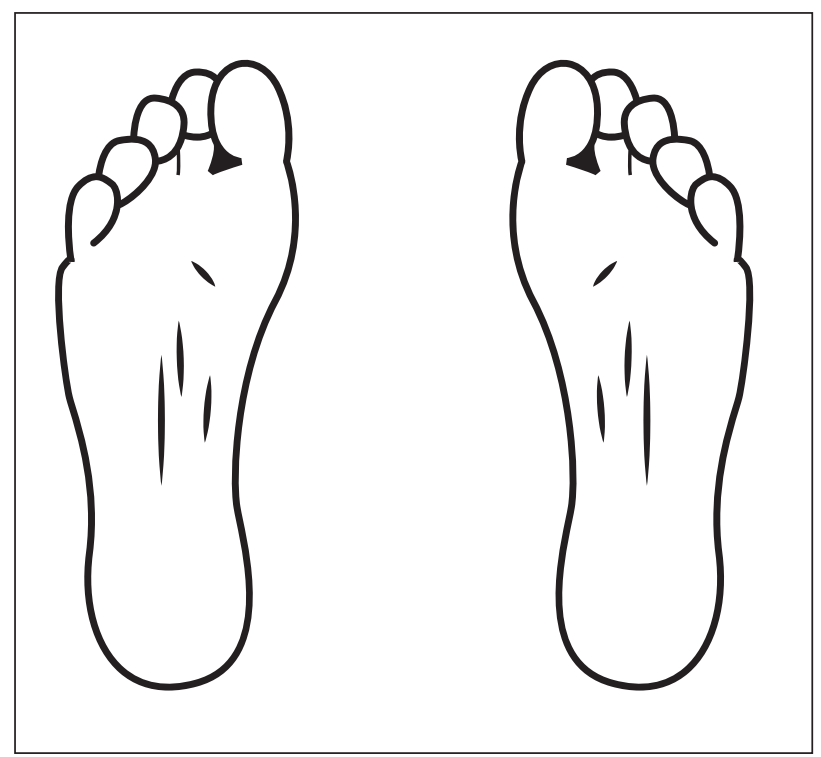

Figure 1 - Placement of the feet during data collection

The variables considered as indicators of body balance were COP displacement amplitude in anteroposterior (COPap) and mid-lateral directions (COPml). These variables were measured by the force platform and given by the following equations:

$$
\begin{aligned}
& \text { COPap }=[(M y-h . F x) / F z] m a x-[(M y-h . F x) / F z] m i n \\
& \text { COPml }=[(M x-h . F y) / F z] m a x-[(M x-h \text {. Fy }) / F z] m i n
\end{aligned}
$$

Of which:

COPAP $=$ force center coordinate in anteroposterior direction;

$\mathrm{COPml}=$ force center coordinate in mid -lateral direction;

$\mathrm{Mx}=$ moment around the anteroposterior axis;
My = moment around the mid-lateral axis;

$\mathrm{Fx}=$ anteroposterior component of soil's reaction force;

Fy = mid-lateral component of soil's reaction force; $\mathrm{Fz}=$ vertical component of soil's reaction force;

$\mathrm{h}=$ surface distance to the geometric center of the force platform.

Throughout the execution of the tests, which were randomly performed, both groups received the same orientations, without receiving visual or auditory stimuli.

\section{Experimental treatment}

The experimental treatment consisted of aquatic exercises for water environment adaptation and initiation to crawl and back strokes swimming, administered three times a week, with each session lasting 50 minutes, through eight consecutive weeks, in the evening period, totalizing 24 sessions. The exercises were conducted by two Physical Education teachers, using auditory and visual stimuli (explanation and demonstration of movements). The exercises routine was gradually developed, according to the learning of movements (Table 1). During classes, auxiliary materials were used to help with floating, such as boards, pull buoys and pool noodles (materials designed to be used in aquatic environments).

The training was executed in a semi-Olympic thermal pool (with $25 \times 12.50 \mathrm{~m}$ of dimension and $1.20 \mathrm{~m}$ of depth at the extremities and $1.60 \mathrm{~m}$ at the central part), with water temperature between 27-30 ${ }^{\circ} \mathrm{C}$. The training description (classes) is illustrated on Table 1.

\section{Statistical analysis}

All data was organized considering the average and standard deviation for each variable in each group. The Shapiro-Wilk test indicated that the data presented normal distribution, and parametric statistical tests were performed then for comparison between groups and situations. OneWay Anova was applied for variable comparison between groups in pre and post-training situations (OE x OE and CE x CE); intra-group in pre and post-training situations ( $\mathrm{OE} \times \mathrm{CE}$ ); and intra-group 
in pre and post-training situations (OE x OE and CE x CE), and Tukey's post-hoc HSD test was used to identify the differences. The significance level adopted for all tests was of 0.05 . The SSPS statistical package for Windows version 15 was used for these analyses.

\section{Results}

The results related to the balance variables COPap and COPml are described in the Figures 2, 3 and 4. In the intra-group assessment conducted during pretraining no variable presented significant statistical difference for both sensory conditions. In post-training, though, both variables in both sensory conditions were found statistically significant (Figure 2). This is an indication that despite the experimental group not showing differences in posture stability in pre-training when compared to the control group, in the post-training, the routine significantly improved postural control, with the experimental group presenting posture oscillation inferior to those of the control group.

Figure 2 demonstrates the comparison between the groups in pre and post-training for both variables analyzed (COPap and COPml).

The comparison between visual conditions wasn't significant for EG in post-training for both variables (COPap and COPml), while in pre-training, visual information was important for both variables (Figure 3). The control group differed in pre and post-training, since visual information was important in both variables. The intra-group comparison revealed significant statistical differences in pre and post-training only for the experimental group, for both variables analyzed (Figure 4).

Figure 3 presents comparisons between visual conditions ( $\mathrm{OE} \times \mathrm{CE}$ ), in pre and post-training for both groups and for both variables analyzed (COPap and COPml).

Figure 4 shows the intra-group comparisons between pre and post-training, for both analyzed variables (COPap and COPml).

Table 1 - Description of the experimental training applied to the experimental group in 24 sessions

\begin{tabular}{|c|c|c|}
\hline Months & Performed activities & Class structure \\
\hline \multirow{2}{*}{$1^{\text {st }}$ month } & $\begin{array}{l}\text { Breathing and posture exercises; } \\
\text { Displacement; } \\
\text { Floating in different decubitus; } \\
\text { Sliding in different decubitus; } \\
\text { Dive }\end{array}$ & \multirow{4}{*}{$\begin{array}{l}2 \text { minutes of stretching; } \\
5 \text { minutes of warming up; } \\
30 \text { minutes of specific content; } \\
10 \text { minutes of recreational activities } \\
3 \text { minutes of stretching. }\end{array}$} \\
\hline & $\begin{array}{l}\text { Breathing and posture exercises; } \\
\text { Learning arms and legs movements for } \\
\text { crawl swimming; } \\
\text { Recreational activities and games with the } \\
\text { aim of fixing the fundamentals }\end{array}$ & \\
\hline \multirow{2}{*}{$2^{\text {nd }}$ month } & $\begin{array}{l}\text { Breathing exercises; } \\
\text { Learning arms and legs movements for } \\
\text { back strokes swimming; } \\
\text { Recreational activities and games with the } \\
\text { aim of fixing the fundamentals }\end{array}$ & \\
\hline & $\begin{array}{l}\text { Breathing exercises; } \\
\text { Crawl swimming; } \\
\text { Back strokes swimming; } \\
\text { Recreational activities and games with the } \\
\text { aim of fixing the fundamentals }\end{array}$ & \\
\hline
\end{tabular}




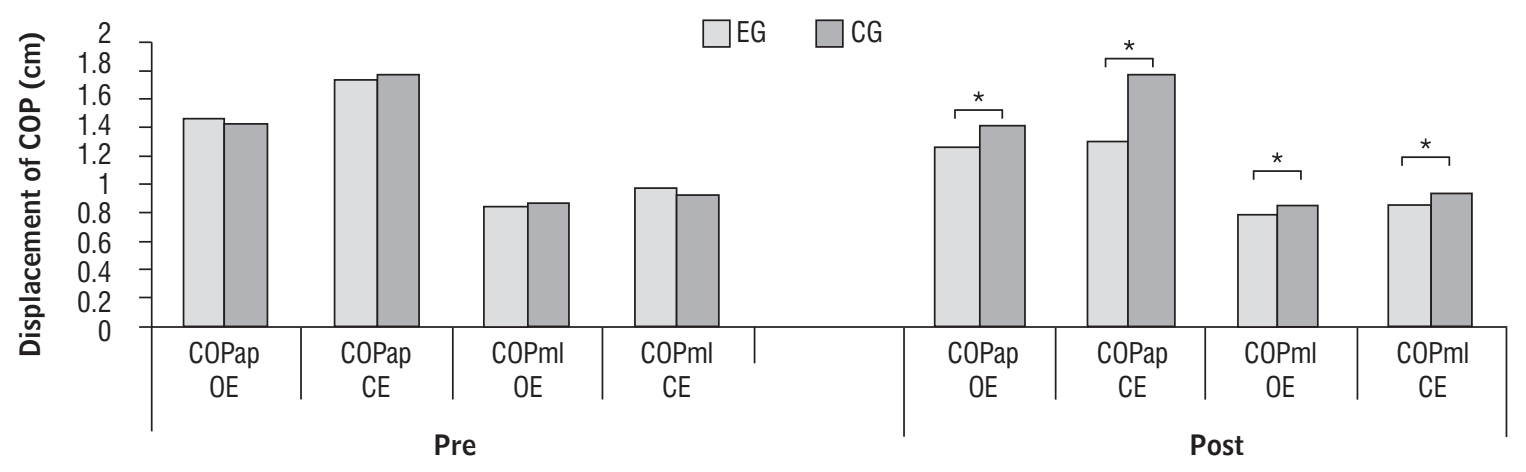

Figure 2 - Results related to the comparison between groups ( $E G \times C G)$ in pre and post-training, in both visual conditions (OE and CE), for both variables analyzed (COPap and COPml)

Note: ${ }^{\star} p<0.05$, statistical difference for comparison between groups in both visual conditions (Tukey).

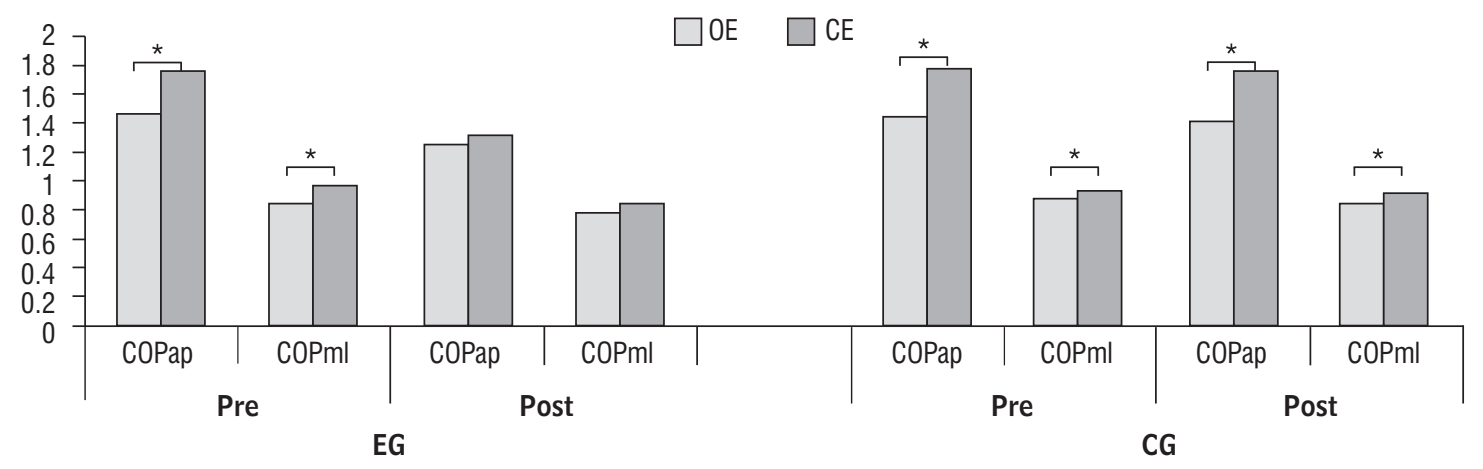

Figure 3 - Results related to visual comparisons (OE x CE) for both groups (CG and EG), in pre and post-training, for both variables analyzed (COPap and COPml)

Note: ${ }^{*} p<0.05$ statistical difference for intra-group comparison between visual conditions (Tukey).

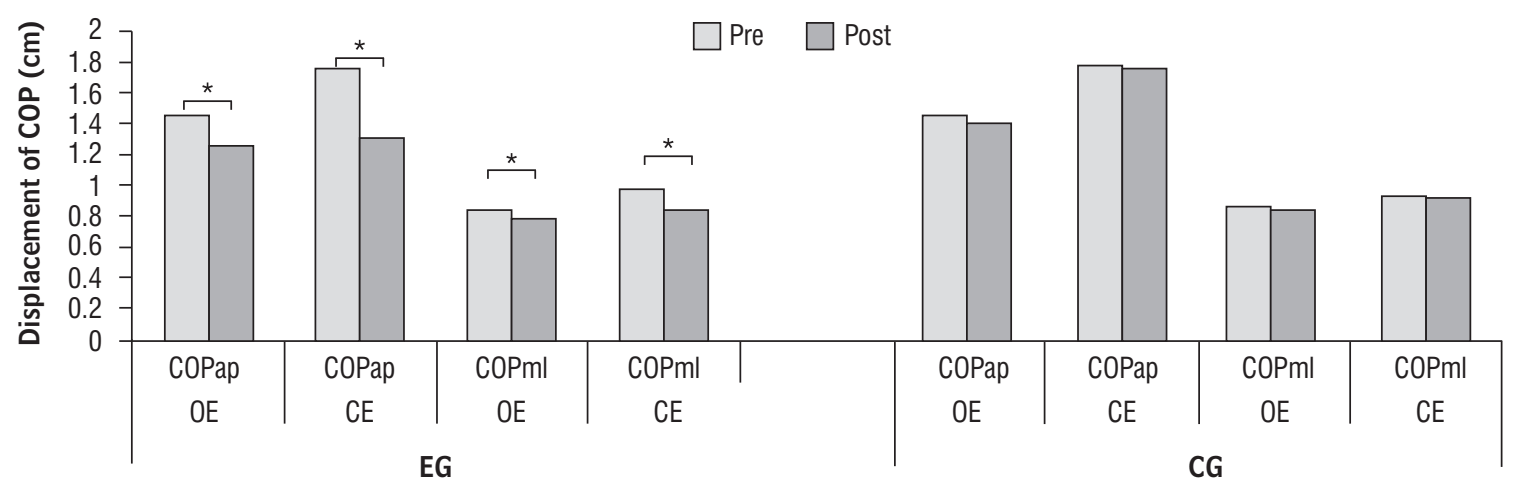

Figure 4 - Results related to intra-group comparisons between pre and post-training, for both variables analyzed (COPap and COPml)

Note: ${ }^{*} p<0.05$ statistical difference for intra-group comparison between pre and post-training (Tukey). 


\section{Discussion}

The aim of this study was the analysis of the influence of an aquatic exercises program on the static body balance in healthy young adults with and without the influence of visual information. The results found suggest that the aquatic exercises program improves static body balance, decreasing the dependence on visual information for posture maintenance.

Literature is scarce when referring to the benefits of physical exercises to enhance posture control in healthy young adults $(16,17,18)$. Thus, the data comparison of the current study is restricted to those reported by literature, since their target audience is predominantly the elderly $(6,10,13,14,19)$ and/or individuals with pathological conditions $(20,21,22)$.

The results of this study corroborate the specialized literature, which substantiate the improvement in body balance after the practice of exercises in aquatic environment $(10,13,14,19)$ once, in posttraining, the COPap and COPml values statistically differed between EG and CG groups, both with open and closed eyes, with GE displaying the lowest oscillation values (Figure 2).

Powers and Howley (12) believe that balance improvement is caused by the water's physical properties that act as aids to joint movement, using the muscles in a more balanced and symmetrical manner, and increasing the variety of body movements.

Similar results to those reported in the current study (Figures 2 and 4 ) regarding the decline in body oscillation after exercises performed in water were found by Mann et al. (10) when demonstrating that the elderly who practice hydrogymnastic keep similar values to sedentary middle-aged adults, and to Alves et al. (23) study that assessed the effects of hydrogymnastic in pre and post-test, and found a gain in the dynamic balance of the female elderly. An explanation to the reduction in body oscillation reported by these studies is that water exercises require a constant body adjustment as to keep the posture in response to water movement, which results in an improvement in body proprioception and synesthesia that provides a higher body posture independence (24).

Improvement on postural control (balance) with the practice of aquatic exercises in relation to the growth in proprioception was reported in Berger et al. study (14), which compares the body balance of the elderly who performed aquatic and soil exercises (16 training sessions with emphasis in exercises for superior and inferior limbs and balance exercises). Corroborating Berger et al. (14), Suomi and Koceja (13) observed that after 18 training sessions (exercises practiced in water with prominence on mobility, flexibility and elasticity improvement) there was a decrease in body instability. In open eyed condition there was a reduction of ca $26 \%$ on posture oscillation in the mid-lateral direction and $18.1 \%$ in total area oscillation after the intervention; in closed eyed condition the decline was observed in three variables (anteroposterior, mid-lateral and total area oscillation), with reduction of $11.5 \%, 30.5 \%$ and $28.5 \%$, respectively. The control group had similar results in pre and post-test.

A significant decrease in body oscillation with absence of vision was also reported in a Mann et al. (21) study that evaluated the influence of a Isostretching program with emphasis in strengthening different muscular groups that act on the maintenance of body posture in female young adult individuals with lumbar pain; in Carpes et al. (20) studies after a 20 sessions program consisting of exercises to strengthen the torso; and in Mann et al. (22) comparison of young adults with and without lumbar pain. Mann et al. (22) indicate that young adult individuals have the ability of keeping their posture hindered in situations of visual deprivation, illustrating that as well as in the elderly of individuals with pathological conditions, vision is an important tool for posture maintenance, both in anteroposterior and mid-lateral direction, which was also evidenced in Chong et al. (25) study.

The results obtained in this study (Figure 3) corroborate the findings in Mann et al. (22), since the pre-test showed that both variables analyzed in both groups were found significant when situations with and without visual information were compared. During post-test the situations with and without vision didn't differ from each other in the experimental group, demonstrating the influence of the training. The control group held similar results in pre and post-training with influence of visual information for posture maintenance (Figure 3).

The results found in the current study suggest the emphasis on available sensory use (mainly somatosensory), since throughout the classes for several times the individuals were forced to perform exercises in which visual information wasn't present. In that sense, Schmid et al. (26) add that for posture maintenance both static and dynamic in healthy individuals, the absence of visual information isn't easily 
compensated by other sensory systems. This, once again, substantiate the results of the current study regarding healthy individuals, who, with training, became less dependent on vision to keep balance.

The decrease of visual dependency reported by the present study, with the practice of aquatic exercises and the decline in COP oscillation as a whole in relation to healthy young adult individuals become particularly important, once the balance of young adult individuals without commitments is usually associated to a healthy life without detriment to their autonomy when performing daily and professional activities, which isn't usually observed with the presence of pathologies such as lumbar pain $(20,21,22)$, vestibular problems (19) or aging process $(10,23)$. Thus, the results of this study demonstrate that the use of programs based on the practice of systemic aquatic exercises is a very important intervention tool, especially when its aim is to decrease existing deficits and avoid falls and musculoskeletal data, among other benefits of regular practice of physical exercises.

\section{Conclusion}

The results of the present study suggest that 24 sessions of systematic aquatic exercises were efficient in balance improvement on healthy young adults, in relation to amplitude decrease in COP displacement in anteroposterior and mid-lateral directions for both sensory conditions analyzed, with the training reducing vision's importance for balance maintenance.

\section{References}

1. Tresch MC. A balanced view of motor control. Nat Neurosci. 10(10):1127-8. Available from: http://dx.doi. org/10.1038/nn1007-1227

2. Perracini MC, Ramos LR. Fatores associados a quedas em uma coorte de idosos residentes na comunidade. Rev Saúde Pública. 2002;36(6):709-16.

3. Duarte M. Análise estabilográfica da postura ereta humana quasi-estática [tese]. São Paulo: Universidade de São Paulo; 2000. Available from: http://demotu. org/pubs/duarte00.pdf
4. Spirduso WW, Francis KL, Macrae PG. Motor control, coordinations and skill. In: Spirduso WW, Francis KL, Macrae PG. Physical dimensions of aging. Champaingn: Human Kinectics; 1995. p. 152-183.

5. Amiridis IG, Hatzitaki V, Arabatzi F. Age-induced modifications of static postural control in humans. Neurosci Lett. 2003;350(3):137-40.

6. Bulbulian R, Hargan ML. The effect of activity history and current activity on static and dynamic postural balance in older adults. Physiol Behav. 2000;70(3-4):319-25.

7. Barnett A, Smith B, Lord SR, Williams M, Baumand A. Community-based group exercise improves balance and reduces falls in at-risk older people: a randomized controlled trial. Age Ageing. 2003;32(4):407-14.

8. Arai T, Obuchi S, Inaba Y, Shiba Y, Satake K. The relationship between physical condition and change in balance functions on exercise intervention and 12-month follow-up in Japanese community-dwelling older people. Arch Gerontol Geriatrics. 2007;48(1):61-6. Available from: http://dx.doi.org/10.1016/j.archger. 2007.10.004

9. Caldwell K, Harrison M, Adams M, Triplett NT. Effect of Pilates and taiji quan training on self-efficacy, sleep quality, mood, and physical performance of college students. J Bodyw Mov Ther. 2008;13(2):155-63. Available from: http://dx.doi.org/10.1016/j.jbmt. 2007.12.001

10. Mann L, Kleinpaul JF, Teixeira CS, Rossi AG, Lopes LFD, Mota CB. Investigação do equilíbrio corporal em idosos. Rev Bras Geriatr Gerontol. 2008;11(2):155-65.

11. Mann L, Kleinpaul JF, Mota CB, Santos SG. Equilíbrio corporal e exercícios físicos: uma revisão sistemática. Motriz Rev Educ Fis. 2009;15(3):713-22.

12. Powers SK, Howley ET. Fisiologia do exercício: teoria e aplicação ao condicionamento e ao desempenho. 5a. ed. São Paulo: Manole; 2000.

13. Suomi R, Koceja DM. Postural sway characteristics in women with lower extremity arthritis before and after an aquatic exercise intervention. Arch Phys Med Rehab. 2000;81(6):780-5. Available from: http://dx.doi. org/10.1016/S0003-9993(00)90111-4 
14. Berger L, Klein C, Commandeur M. Evaluation of the immediate and midterm effects of mobilization in hot spa water on static and dynamic balance in elderly subjects. Ann Méd Phys Réadapt. 2008;51(2): 90-5. Available from: http://dx.doi.org/10.1016/j. annrmp.2007.10.007

15. Winter DA. Biomechanics and motor control of human movement. New York: Wiley; 1990.

16. Kovacs EJ, Birmingham TB, Forwell L, Litchfield RB. Effect of training on postural control in figure skaters: a randomized controlled trial of neuromuscular versus basic off-ice training programs. Clin J Sports Med. 2004;14(4):215-24.

17. Biec E, Kuczynski MK. Postural control in 13-yearold soccer players. Eur J Appl Physiol. 2010;110(4): 703-8. Available from: http://dx.doi.org/10.1007/ s00421-010-1551-2

18. Clifford AM, Holder-Powell H. Postural control in healthy individuals. Clin Biomech. 2010;25(6):546-51.

19. Teixeira CS. Hidroginástica na reabilitação vestibular para idosos com queixas de tontura [dissertação]. Santa Maria: Universidade Federal de Santa Maria; 2008. Available from: http://jararaca.ufsm.br/websites/ ppgdch/c9f060ca0577501686bfce0e1a564e43.htm

20. Carpes FP, Reinehr FB, Mota CB. Effects of a program for trunk strength and stability on pain, low back and pelvis kinematics, and body balance: a pilot study. J Bodyw Mov Ther. 2008;12(1):22-30. Available from: http://dx.doi.org/10.1016/j.jbmt.2007.05.001

21. Mann L, Kleinpaul JF, Weber P, Mota CB, Carpes FP. Efeito do treinamento de Isostretching sobre a dor lombar crônica: um estudo de casos. Motriz Rev Educ Fis. 2009;5(1):50-60.
22. Mann L, Kleinpaul JF, Moro ARP, Mota CB, Carpes FP. Effect of low back pain on postural stability in younger women: influence of visual deprivation. J Bodyw Mov Ther. 2009;14(4):361-6. Available from: http://dx.doi. org/10.1016/j.jbmt.2009.06.007

23. Alves RV, Mota J, Costa MC, Alves JGB. Aptidão física relacionada à saúde de idosos: influência da hidroginástica. Rev Bras Med Esporte. 2004;10(1):31-7.

24. Ruoti RG, Morris DM, Cole AJ. Reabilitação aquática. São Paulo: Manole; 2000.

25. Chong RKY, Mills B, Dailey L, Lane E, Smith S, Lee K. Specific interference between a cognitive task and sensory organization for stance balance control in healthy young adults: Visuospatial effects. Neuropsychologia. 2010;48(9):2709-18.

26. Schmid M, Nardone A, De Nunzio AM, Schmid M, Schieppati M. Equilibrium during static and dynamic tasks in blind subjects: no evidence of cross-modal plasticity. Brain. 2007;130(8):2097-107. Available from: http://dx.doi.org/10.1093/brain/awm157

Received: $12 / 26 / 2013$

Recebido: 26/12/2013

Approved: 07/14/2014

Aprovado: $14 / 07 / 2014$ 